\title{
Sociobiodiversidade e alimentação escolar: uma experiência no Litoral Norte do Rio Grande do Sul
}

\author{
Sociobiodiversity and school feeding: an experience in the North Coast of Rio \\ Grande do Sul
}

\section{Sociobiodiversidad y alimentación escolar: una experiencia en la costa norte de Rio Grande do Sul}

\author{
Vanessa Magnus Hendler ${ }^{1}$ \\ Luciana Dias de Oliveira ${ }^{1}$ \\ Martine Elisabeth Kienzle Hagen ${ }^{1}$ \\ Andrea Mónica Solans ${ }^{2}$ \\ Queite Marrone Soares da Silva ${ }^{1}$ \\ Louise Barbosa Palma ${ }^{1}$ \\ Vanuska Lima da Silva ${ }^{1}$ \\ Alessandro de Oliveira Rios ${ }^{1}$ \\ Larissa Mont'Alverne Jucá Seabra ${ }^{3}$ \\ Eliziane Nicolodi Francescato Ruiz ${ }^{1}$
}

Recebido em: 06/01/2020; revisado e aprovado em: 13/11/2020; aceito em: 31/03/2021

DOI: http://dx.doi.org/10.20435/inter.v22i3.3217

\begin{abstract}
Resumo: O Programa Nacional de Alimentação Escolar é uma das mais importantes políticas de Segurança Alimentar e Nutricional no Brasil, viabilizando a oferta de uma alimentação saudável e adequada a todos os estudantes matriculados na rede pública da educação básica e criando mercados para agricultores familiares. Nesse sentido, partindo do entendimento de que a inserção de alimentos que dialoguem com a sustentabilidade e a cultura alimentar na alimentação escolar poderiam desencadear diversos efeitos positivos no contexto local, este artigo busca relatar as ações iniciais de um projeto maior, desenvolvido no município de Mostardas, que perpassa pela temática da alimentação escolar e da sociobiodiversidade, descrevendo as apreensões sobre o valor sociocultural e nutricional de alimentos da sociobiodiversidade, bem como o papel da escola e da alimentação escolar para a comunidade local. Para tal, esta etapa da pesquisa compreendeu duas fases: a primeira consistiu em um momento de interação com os atores locais, no qual se apreenderam histórias, significados e saberes sobre receitas à base de alimentos da sociobiodiversidade, como o feijão-sopinha e o milho-catete; e a segunda abrangeu a realização da análise de composição química centesimal e de fibras dos referidos alimentos. A partir dos relatos dos participantes, pôde-se compreender o valor sociocultural de alimentos e preparações que remontam a sua cultura e a sua história de vida, assim como a importância, conferida pela comunidade à escola e à alimentação escolar, no que tange à formação dos hábitos alimentares dos alunos. Para além das apreensões no plano simbólico, a caracterização química revelou o potencial nutricional do feijão-sopinha e do milho-catete, os quais se mostraram nutricionalmente superiores quando comparados a outros feijões e milho de consumo habitual dos brasileiros.
\end{abstract}

Palavras-chave: segurança alimentar e nutricional; sociobiodiversidade; alimentação escolar.

Abstract: The National School Feeding Program is one of the most important policies for Food and Nutritional Security in Brazil, enabling the provision of healthy and adequate food to all students enrolled in the public basic education network and creating markets for family farmers. In this sense, based on the understanding that the insertion of food that dialogues with sustainability and food culture in school feeding could trigger several positive effects in the local context, this article seeks to report the initial actions of a larger project, developed in the municipality of Mostardas, which runs through the theme of school feeding and sociobiodiversity, describing concerns about the sociocultural and nutritional value of foods from sociobiodiversity, as well as the role of schools and school feeding for the local community. To this end, this stage of the research comprised

\footnotetext{
${ }^{1}$ Universidade Federal do Rio Grande do Sul (UFRGS), Porto Alegre, Rio Grande do Sul, Brasil.

${ }^{2}$ Universidade de Buenos Aires (UBA), Buenos Aires, Argentina.

${ }^{3}$ Universidade Federal do Rio Grande do Norte (UFRN), Natal, Rio Grande do Norte, Brasil.
} 
two phases: the first consisted of a moment of interaction with the local actors, in which are seized stories, meanings, and knowledge about recipes based on sociobiodiversity foods, such as sopinha bean and catete corn, and the second that included the analysis of chemical composition and fibers of these foods. From the reports of the participants, it is possible to understand the sociocultural value of food and preparations that go back to their culture and their life history, as well as the importance given by the community to the school and school meals, concerning the training students' eating habits. In addition to the symbolic apprehensions, the chemical characterization revealed the nutritional potential of sopinha bean and catete corn, which proved to be nutritionally superior when compared to other beans and corn of habitual consumption by Brazilians.

Keywords: food and nutrition security; sociobiodiversity; school feeding.

Resumen: El Programa Nacional de Alimentación Escolar es una de las políticas más importantes para la Seguridad Alimentaria y Nutricional en Brasil, que permite la provisión de alimentos saludables y adecuados a todos los estudiantes inscritos en la red pública de educación básica y crea mercados para los agricultores familiares. En este sentido, a partir del entendimiento de que la inserción de alimentos que dialoguen con la sostenibilidad y la cultura alimentaria en la alimentación escolar podrían desencadenar varios efectos positivos en el contexto local, este artículo busca reportar las acciones iniciales de un proyecto mayor, desarrollado en el municipio de Mostardas, que aborda el tema de las comidas escolares y la sociobiodiversidad, describiendo preocupaciones sobre el valor sociocultural y nutricional de los alimentos de la sociobiodiversidad, así como el papel de las escuelas y de las comidas escolares para la comunidad local. Para ello, esta etapa de la investigación comprendió dos fases: la primera consistió en un momento de interacción con los actores locales, en que se aprendieron historias, significados y conocimientos sobre recetas basadas en alimentos de sociobiodiversidad, como frijol sopinha y maíz catete; y el segundo incluyó el análisis de composición química y fibras de estos alimentos. A partir de los relatos de los participantes, es posible comprender el valor sociocultural de los alimentos y preparaciones que se remontan a su cultura y su historia de vida, así como la importancia que la comunidad le da a la escuela y la alimentación escolar, en lo que respecta a la formación de los hábitos alimenticios de los estudiantes. Además de las aprehensiones a nivel simbólico, la caracterización química reveló el potencial nutricional de frijol sopinha y maíz catete, que fueron nutricionalmente superiores en comparación otros frijoles y maíz de consumo habitual por brasileños.

Palabras clave: seguridad alimentaria y nutricional; sociobiodiversidad; alimentación escolar.

\section{INTRODUÇÃO}

O Programa Nacional de Alimentação Escolar (PNAE) consolidou-se como uma das mais importantes e longevas políticas de Segurança Alimentar e Nutricional (SAN) em execução no Brasil, desempenhando papel essencial na garantia do Direito Humano à Alimentação Adequada (DHAA) (BRASIL, 2009a; 2014a). Desde a sua constituição na década de 1950, o PNAE avançou em inúmeros aspectos, sobretudo a partir de 2009, por meio da Lei n. 11.947, que incorpora o desenvolvimento sustentável e o respeito à cultura alimentar nas suas diretrizes. Desse modo, a partir do referido marco legal, há uma maior preocupação em adequar o cardápio escolar à realidade local, coadunando aspectos nutricionais, de saúde, a vocação agrícola da região, o respeito às singularidades do território e às tradições alimentares (BRASIL, 2009a).

Apesar dos estímulos para a aquisição e inserção de alimentos que valorizem a biodiversidade regional e respeitem a cultura alimentar local na alimentação escolar, estudos (SOUSA et al., 2015; GIRARDI et al., 2018; GABRIEL et al., 2012) vêm apontando cardápios escolares pouco diversificados e desprovidos de referências locais, que pouco exploram "as infinitas possibilidades que os biomas brasileiros e suas populações apresentam quanto à diversidade de alimentos e às maneiras de prepará-los" (SOUSA et al., 2015, p. 223). Ademais, emerge a discussão acerca do fenômeno da globalização da alimentação que se materializa na substituição de padrões alimentares tradicionais centrados no consumo de alimentos locais por produtos "globais", como fast-food e alimentos ultraprocessados ${ }^{4}$, configurando um processo de homogeneização e/ou

\footnotetext{
${ }^{4}$ A segunda edição do Guia Alimentar para a População Brasileira (BRASIL, 2014b) apresenta uma classificação
} 
pasteurização do gosto alimentar. Ou seja, o comer e as opções alimentares tornam-se muito similares em diferentes lugares do mundo (POPKIN, 2014; MONTEIRO et al., 2017; CONTRERAS, 2005; RIBEIRO; JAIME; VENTURA, 2017).

Com relação aos efeitos desse sistema de produção e consumo, o que se observa são consequências negativas desde os planos da saúde, com a coexistência de obesidade, má nutrição, doenças crônicas não transmissíveis (DCNT) - tais como diabetes, hipertensão e doenças cardiovasculares - e desnutrição, até repercussões sobre os planos culturais e simbólicos da alimentação, como a perda de conhecimentos tradicionais, práticas e significados que constituem as identidades alimentares, chegando ao plano biológico, ocasionando a perda de variedades vegetais, animais e de nutrientes (JOHNS; EYZAGUIRRE, 2006; CONTRERAS, 2005; MACIEL, 2005).

No entanto, na contramão desse cenário, discutem-se também algumas possibilidades e capacidades imbuídas na inter-relação entre alimentação escolar e sociobiodiversidade regional, que, ao trabalhar com a perspectiva de inserção de tais alimentos nos cardápios escolares, poderia tanto melhorar a qualidade das refeições servidas na escola, em termos nutricionais, como contribuir com a conservação dos ecossistemas e a reafirmação sociocultural das comunidades. Ou seja, os efeitos desse movimento não se restringiriam ao espaço escolar, expandindo-se a todo o território (SOUSA et al., 2015; GIRARDI et al., 2018; CARVALHO; OLIVEIRA E SILVA, 2014; TRICHES; SCHNEIDER, 2010; BRASIL, 2017a).

A categoria sociobiodiversidade surge no contexto brasileiro como fruto de um processo de mobilização e luta coletiva dos povos e comunidades tradicionais e agricultores familiares por justiça social, desenvolvimento sustentável, geração de renda, preservação da biodiversidade e conhecimentos tradicionais, carregando também expressivo valor político e social (BRASIL, 2006; COELHO-DE-SOUZA, 2012). O resultado dessa mobilização se materializou na publicação do Plano Nacional de Promoção de Cadeias de Produtos da Sociobiodiversidade (PNPSB), em 2009 (BRASIL, 2009b), que reconhece e define produtos da sociobiodiversidade como:

Bens e serviços (produtos finais, matérias primas ou benefícios) gerados a partir de recursos da biodiversidade, voltados à formação de cadeias produtivas de interesse dos povos e comunidades tradicionais e de agricultores familiares, que promovam a manutenção e valorização de suas práticas e saberes, e assegurem os direitos decorrentes, gerando renda e promovendo a melhoria de sua qualidade de vida e do ambiente em que vivem. (BRASIL, 2009b, p. 9).

Partindo de tal entendimento, ressalta-se a inter-relação entre a diversidade biológica e a diversidade cultural, compreendendo a indissociabilidade entre os planos ambientais e socioculturais, sobretudo nos contextos de países megabiodiversos e de grande diversidade cultural, como o Brasil (COELHO-DE-SOUZA, 2012). Desta forma, as práticas de cultivo e uso das espécies nativas estão intimamente atreladas aos diferentes modos de vida, crenças e conhecimentos tradicionais compartilhados entre povos e comunidades tradicionais e agricultores familiares (SANTILI, 2009).

dos alimentos conforme o seu grau de processamento, sendo estes categorizados em: alimentos in natura ou minimamente processados, ingredientes culinários, alimentos processados e alimentos ultraprocessados. Alimentos ultraprocessados são formulações industriais à base de substâncias extraídas ou derivadas de alimentos (óleos, gorduras, açúcar, amido) e/ou produzidas em laboratório (corantes, aromatizantes, realçadores de sabor, entre outros aditivos alimentares). Esses produtos costumam ter em seus rótulos listas enormes de ingredientes. 
Como forma de reconhecimento da diversidade biológica e sociocultural, além da PNPSB, foram criadas, na esfera federal, algumas iniciativas a fim de promover e fortalecer as cadeias de produtos da sociobiodiversidade, no âmbito dos mercados institucionais, como o PNAE. Em 2021, por exemplo, foi lançada a Portaria Interministerial MAPA/MMA n. 10 - atualizando a Portaria Interministerial n. 284, de 2018 -, a qual apresenta uma lista de produtos da sociobiodiversidade com potencial para serem incorporados em programas como o da Alimentação Escolar (BRASIL, 2018a; 2021). Ademais, para garantir condições justas de comercialização e viabilização de mercados, estabeleceu-se a Política de Garantia de Preços Mínimos para os Produtos da Sociobiodiversidade (PGPM-Bio), assegurando preços mínimos para mais de 17 produtos extrativistas (BRASIL, 2019).

No âmbito internacional, destaca-se o projeto "Biodiversidade para Alimentação e Nutrição" - BFN, coordenado internacionalmente pelo Bioversity International (formalmente conhecido como Instituto Internacional de Recursos Genéticos Vegetais [IPGRI]), tendo como agências implementadoras o Programa das Nações Unidas para o Meio Ambiente (PNUMA) e a Organização das Nações Unidas para a Alimentação e a Agricultura (FAO). No Brasil, as atividades foram coordenadas pelo Ministério do Meio Ambiente em colaboração com diferentes setores do Governo Federal e parcerias realizadas junto a universidades e instituições de pesquisa de todo o país. Com o intuito de proporcionar o reconhecimento do valor alimentício e nutricional das espécies nativas brasileiras e visibilizar a possibilidade de intersecção em políticas públicas como o PNAE, o BFN construiu um banco de dados sobre a biodiversidade nacional, que reúne informações sobre composição nutricional, receitas, saberes tradicionais e mapeamento da distribuição geográfica de tais espécies (BRASIL, 2018b).

Na esfera regional, destaca-se, no Rio Grande do Sul (RS), as ações da Cadeia Solidária das Frutas Nativas (CSFN), que, enquanto uma rede, articula instituições ligadas à agroecologia e à economia solidária e atua com foco na valorização e difusão do consumo das frutas nativas do estado. As ações dessa rede ocorrem por meio de encontros e reuniões, nos quais discutemse aspectos relacionados à produção, a custos, mercados, estratégias de comercialização, desenvolvimento de produtos, entre outras questões (RAMOS et al., 2017).

Seguindo essa ótica de fortalecer a relação entre sociobiodiversidade e alimentação escolar, vem sendo executado em esfera local, no município de Mostardas, localizado no Litoral Norte do Rio Grande do Sul, uma pesquisa-ação multicêntrica e interdisciplinar ${ }^{5}$, denominada "Alimentação adequada e saudável no contexto da alimentação escolar: difusão do consumo de produtos da sociobiodiversidade regional". O projeto foi contemplado em edital do Conselho Nacional de Desenvolvimento Científico e Tecnológico (CNPq)/MCTIC N. 016/2016 e teve como foco trabalhar práticas de alimentação saudável em escolas por meio da inclusão de alimentos da sociobiodiversidade. O projeto compreende três etapas: 1) aproximação com a comunidade e desenvolvimento da oficina culinária; 2) análise físico-química de alimentos da sociobiodiversidade; 3) aplicação de testes de adesão e aceitabilidade de preparações à base de alimentos da sociobiodiversidade nas escolas públicas do município de Mostardas.

Para iniciar o projeto e prosseguir com o trabalho de inserção da sociobiodiversidade na alimentação escolar, foi necessário, então, abordar primeiramente questões como: quais

\footnotetext{
${ }^{5}$ A pesquisa partiu da interface entre o campo da Nutrição com outros campos disciplinares, como da Antropologia, Biologia e o campo do Desenvolvimento Rural, que é interdisciplinar por natureza. Além disso, o projeto vem sendo executado em parceria com a Universidade Federal do Rio Grande do Norte (UFRN) e a Universidade de Buenos Aires (UBA), na Argentina.
} 
as preparações e os ingredientes da sociobiodiversidade utilizados pela comunidade local? Quais os sentidos atribuídos a esses alimentos? Partindo dos aspectos normativos em que os cardápios escolares precisam ter especificado as características nutricionais das preparações, qual a composição nutricional dos alimentos da sociobiodiversidade que poderiam fazer parte da alimentação escolar?

A partir do exposto, este artigo tem como objetivo descrever o que, no âmbito das ações iniciais do projeto supracitado (na sua primeira e segunda etapas), apreendeu-se sobre o valor sociocultural e nutricional de alimentos considerados da sociobiodiversidade, bem como o papel da escola na comunidade local, especialmente em se tratando da alimentação oferecida aos escolares.

Parte-se do pressuposto de que discutir a inserção de alimentos da sociobiodiversidade no PNAE, tendo como centralidade a perspectiva das comunidades locais, possibilita refletir sobre os desafios, as potencialidades e os mecanismos mais profundos que seriam importantes para que, em cada contexto, possa se avançar no aprimoramento das políticas de Segurança Alimentar e Nutricional.

Além desta parte introdutória, o trabalho está organizado em outras três seções, sendo a seguinte relacionada à apresentação do contexto empírico do trabalho e dos recursos metodológicos utilizados na produção e discussão dos dados. Na sequência, apresentam-se os resultados do trabalho, na qual se disserta sobre o valor sociocultural e nutricional que os alimentos como o feijão-sopinha e o milho-catete têm para a comunidade local e para a alimentação escolar. E, por fim, apresentam-se as considerações finais, destacando as principais apreensões do estudo.

\section{METODOLOGIA}

O município de Mostardas está situado no Litoral Norte do estado do Rio Grande do Sul, entre a Lagoa dos Patos e o Oceano Atlântico. Em virtude da sua localização, o município possui um ecossistema complexo que the confere algumas características peculiares com relação à biodiversidade circunscrita, que se manifesta em uma pluralidade de paisagens (dunas e campos litorâneos, matas de restinga, banhados, sangas, lagoas e mar) e em grande diversidade biológica (CASAGRANDE, 2012; PELEGRINI, 2012). Ademais, a região abrange o Parque Nacional da Lagoa do Peixe (PNLP), uma das principais unidades de conservação do sul do país, abrigando uma grande variedade de aves migratórias e uma ampla diversidade de espécies (algas, plantas aquáticas, macroinvertebrados, anfíbios, répteis, aves e mamíferos), algumas ameaçadas de extinção (PELEGRINI, 2012).

Além da origem açoriana, compõe a ancestralidade mostardense, os descendentes de antigos escravos, que, diante de um contexto social, político e histórico, refugiavam-se em determinados territórios constituindo os Quilombos (PEREIRA; PEREIRA; PEREIRA, 2008 apud VANINI, 2010, p. $63)^{6}$. Atualmente, no município, há três comunidades remanescentes de quilombos certificadas pela Fundação Cultural Palmares: Beco dos Coloidianos, Casca e Teixeiras ${ }^{7}$. A principal atividade econômica desses grupos é a agricultura familiar, sendo parte dos alimentos utilizados para consumo

\footnotetext{
${ }^{6}$ PEREIRA, S. D.; PEREIRA, D. J.; PEREIRA, R. A. Quilombolas. In: Mostardas e Tavares sob as lentes do turismo. Mostardas: Pallotti, 2008. p. 88-93.

7 Disponível no site da Fundação Cultural Palmares, em: http://www.palmares.gov.br/wp-content/uploads/2015/07/ certificadas-02-08-2019.pdf. Acesso em: 30 out. 2020.
} 
próprio e a outra comercializada em feiras (RAMOS, 2011; VANINI, 2010). Alguns membros das famílias trabalham ainda nas plantações de arroz próximas às comunidades. Cabe ressaltar que o avanço da rizicultura, da soja e do cultivo de pinus na região vem ocasionando a perda da diversidade genética, além de outros impactos ambientais e sociais (CASAGRANDE, 2012).

O foco do projeto voltou-se, especialmente, para o feijão-sopinha e o milho-catete. Esses alimentos são produzidos em Mostardas, por agricultores familiares e comunidades tradicionais, mas vêm perdendo espaço ante os avanços das monoculturas e da incorporação de outros gêneros alimentícios na alimentação da população, conforme relatos de lideranças locais e integrantes da Cooperativa dos Povos Tradicionais de Mostardas (COOPTRAM), em aproximações que o grupo de pesquisa vinha fazendo com a região. É importante destacar que o feijão-sopinha não é uma espécie nativa, mas ambos são reconhecidos como alimentos "locais". Apesar dos alimentos envolvidos no estudo não estarem descritos na lista de produtos da sociobiodiversidade, nós os compreendemos como tais, em virtude de suas peculiaridades de produção e consumo na região. Atualmente, esses alimentos são produzidos, sobretudo, pelas comunidades quilombolas, e sua produção, preparo e consumo são envoltos em práticas culturais que passaram de pais para filhos. O consumo, em especial, acontece em momentos de reuniões de trabalho ou de lazer (festividades e encontros de família), quando histórias sobre o feijão e o milho são relembradas e resgatadas. Outra questão importante para o entendimento é que as mulheres da comunidade são as detentoras do conhecimento sobre as formas de preparo, o qual costuma ser repassado das mais velhas para as mais jovens.

Buscando uma aproximação maior com a comunidade e a apreensão dos questionamentos iniciais para se avançar nas ações do projeto que visava trabalhar com a inclusão do feijão-sopinha e milho-catete na alimentação escolar de Mostardas, organizou-se um encontro com alguns atores locais: agricultoras(es) familiares, representantes de comunidades quilombolas, manipuladoras de alimentos das escolas do município e gestores locais. O encontro, considerado a primeira etapa do projeto maior, ocorreu no salão comunitário do município, desenvolvendo-se em dois momentos, nos quais foram produzidas as principais informações sobre o valor sociocultural dos alimentos da sociobiodiversidade e o papel da escola. Destaca-se que observações participantes e contatos/conversas com lideranças locais também foram realizadas ao longo do percurso de todo o projeto e auxiliaram na produção das informações.

No primeiro momento do encontro, os participantes foram incentivados a discorrer sobre práticas alimentares que remetiam a sua origem histórica e cultural. Para tanto, o grupo foi conduzido a identificar alimentos que estivessem relacionados à sua história de vida. De forma espontânea, foram trazendo memórias das suas infâncias e relatos sobre o feijão-sopinha e o milho-catete. Também, neste primeiro momento, os participantes fizeram uma demonstração do uso do pilão, referido como símbolo da cultura dos povos tradicionais da região, preparando uma farinha (farinha de cachorro) à base de milho-catete, amendoim torrado, amaranto (caruru) e açúcar mascavo (Foto 1). Considerada extremamente nutritiva, a preparação era muito consumida pelos agricultores mais antigos, que levavam o alimento para a "roça", local no qual permaneciam por longas horas de trabalho.

Em um segundo momento, foi realizada uma oficina culinária na cozinha do salão comunitário, para a execução de receitas que continham como principais ingredientes o feijãosopinha e o milho-catete, produzidos pela agricultura familiar local. As preparações foram escolhidas e reproduzidas por seis mulheres que participavam da atividade (Foto 2 ). 
Figura 1 - Pilão

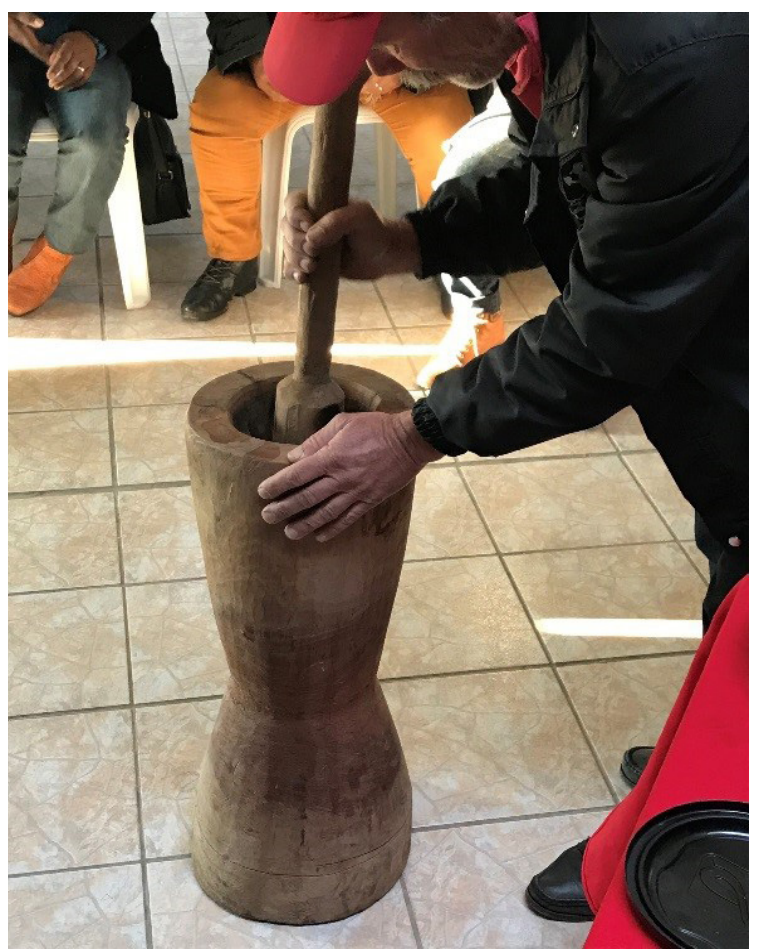

Fonte: Projeto Alimentação Adequada e Saudável no Contexto da Alimentação Escolar: Difusão do Consumo de Produtos da Sociobiodiversidade Regional, 2018.

Figura 2 - Oficina culinária

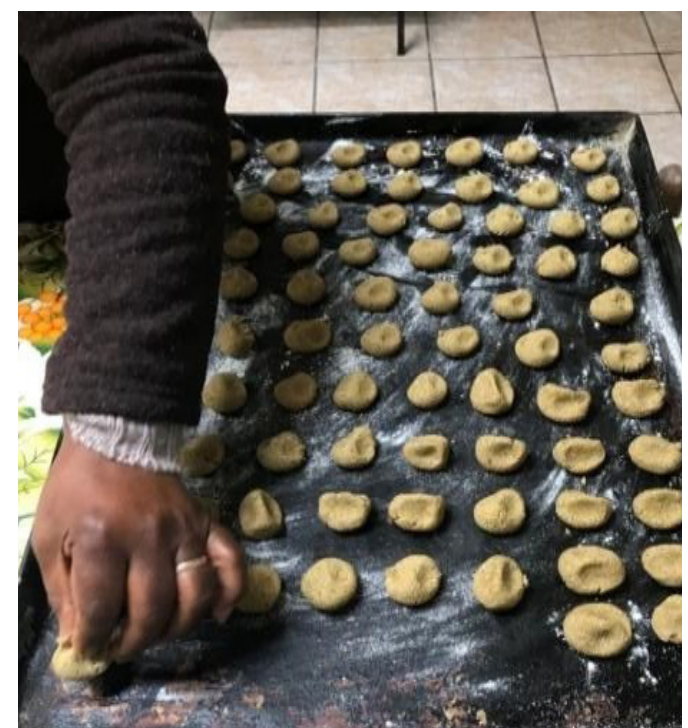

Fonte: Projeto Alimentação Adequada e Saudável no Contexto da Alimentação Escolar: Difusão do Consumo de Produtos da Sociobiodiversidade Regional, 2018.

No decorrer das preparações, as mulheres deixavam transcorrer as lembranças que cada alimento Ihes trazia. Simultaneamente ao preparo das receitas, realizou-se o registro delas para que, posteriormente, fossem confeccionadas as fichas técnicas de preparo, instrumento 
requerido no âmbito da produção das refeições da alimentação escolar. Esta ferramenta foi ainda utilizada na terceira etapa do projeto, que consistiu na aplicação, junto aos escolares, dos Testes de Adesão e Aceitabilidade das preparações a serem inseridas nos cardápios escolares ${ }^{8}$. Além disso, realizou-se um almoço coletivo com a degustação de todas as preparações elaboradas.

Em ambos os momentos, os depoimentos dos participantes foram gravados por meio de dispositivo eletrônico (gravador), sendo realizado também registro fotográfico das preparações. Após a transcrição na íntegra do material empírico, os quais serão apresentados nos resultados sem correção ortográfica, realizou-se a análise qualitativa dos dados por meio da Análise de Conteúdo do tipo temático, proposto por Minayo (2007). Operacionalmente, a autora divide em três etapas: pré-análise, exploração do material e tratamento dos resultados obtidos e interpretação. Os resultados são apresentados a partir de temáticas que apareceram como respostas ao objetivo de apreender o significado do alimento local e do comer na escola, e à luz de referenciais da socioantropologia da alimentação.

Em uma segunda etapa do projeto, utilizando-se de abordagem do campo da Nutrição, foram realizadas as análises de composição química centesimal e de fibras do milho-catete e do feijão-sopinha, a fim de se conhecer o valor nutricional desses alimentos. Essa também é uma etapa considerada necessária para a terceira fase de inserção dos alimentos da sociobiodiversidade na alimentação escolar de Mostardas.

Para tal, foram coletadas amostras de alimentos no próprio município, no ano de 2018. As amostras foram trituradas em moinho de faca: knifemill (Solab, model SL-31, Brazil), a fim de obter as farinhas cruas. Após trituração, foram armazenadas em freezer a-18ㄷ․ As análises bromatológicas de composição química foram determinadas segundo as normas da Association of Oficial Analytical Collaboration (AOAC) International (1997) e Carvalho et al. (2002), por meio dos métodos: Proteínas: método Kjeldahl, em um equipamento Velp Scientifica com unidade de digestão DK 20. Lipídeos: método de Gelber, método gravimétrico de Schmid-BondzynskiRatzlaff, segundo a norma FIL-IDF 5B, e método gravimétrico Goldfish. Cinza total: método gravimétrico por incineração em mufla. Método fundamentado na perda de peso que ocorre quando o produto é incinerado a 500ㄷ-560들 segundo norma Fil-IDF 27. Umidade: por meio do uso de MA 30 Misture Analyzer da Sartorius (Alemanha). O teor de fibra dietética total foi determinado de acordo com o método enzimático gravimétrico de Prosky et al. (1988). Os carboidratos totais foram determinados por diferença; o valor calórico foi estimado por meio dos fatores de conversão de ATWATER: 4 kcal.g-1 para proteínas, 4 kcal.g-1 para carboidratos e 9 kcal.g-1 para lipídios.

Os resultados das análises são apresentados como média + DP (desvio-padrão) para cada uma das medidas realizadas em triplicata. Foi realizada estatística descritiva para apresentação dos valores das medidas e utilizado o teste t de Student para verificar a diferença entre os resultados encontrados e os valores de composição química centesimal de feijão-preto e de farinha de milho amarela descritos na Tabela Brasileira de Composição de Alimentos (NÚCLEO DE ESTUDOS E PESQUISAS EM ALIMENTAÇÃO [NEPA], 2011). Foi considerado um nível de significância de $5 \%(p<0,05)$ e um intervalo de confiança de $95 \%$. Os dados foram analisados com o programa estatístico Statistical Package for the Social Sciences (SPSS) versão 21.0.

\footnotetext{
${ }^{8}$ De acordo com a legislação do PNAE, a inserção de novos alimentos no cardápio escolar deve ser avaliada quanto a sua aceitação por parte dos estudantes, por meio da realização dos testes de aceitabilidade, conforme metodologia recomendada pelo Fundo Nacional de Desenvolvimento da Educação (FNDE) (BRASIL, 2017b).
} 
Esta pesquisa foi aprovada pelo Comitê de Ética em Pesquisa da Universidade Federal do Rio Grande do Sul, sob protocolo de n. 82570018.2.1001.5347.

\section{RESULTADOS E DISCUSSÃO}

\subsection{Entre histórias, sabores e saberes: o valor sociocultural dos alimentos da sociobiodiversidade}

Esta seção dissertará, a partir de descrições e interfaces analíticas principalmente do campo da Antropologia da Alimentação, sobre a história e o valor sociocultural que os alimentos da sociobiodiversidade, especialmente o feijão-sopinha e o milho-catete, representam para a comunidade de Mostardas.

Conforme os relatos dos participantes, o feijão-sopinha veio da África, sendo trazido escondido no cabelo das mulheres escravizadas, durante o tráfico negreiro, como forma de patuá (amuleto) e para garantir o sustento (alimento) nas terras desconhecidas: "[...] usavam 3 sementinhas do feijão sopinha como um patuá, para proteger a alma e o espírito" (Participante 3).

Este feijão era muito consumido pelos remanescentes de quilombo, tornando-se conhecido como "comida da senzala". Tempos mais tarde, o feijão-sopinha, conforme relatos, passou a ser consumido também na "casa grande" pelos senhores de engenho, que passaram a apreciá-lo e, inclusive, a incluí-lo nas festividades de casamento, pois a oferta e o consumo do alimento na ocasião simbolizavam fertilidade e felicidade aos noivos. O feijão-sopinha também fazia e ainda faz, entretanto com menor frequência, parte da festividade religiosa afro-brasileira denominada de "Ensaio de Pagamento de Promessa". A expressão cultural pode estar relacionada a diferentes situações, compreendendo desde pedidos "de graça" referentes a situações de crise/conflitos, a agradecimentos pela "dádiva" alcançada e pagamento da promessa a Nossa Senhora do Rosário. De acordo com Lobo (2010), que pesquisou essa manifestação cultural no contexto das comunidades quilombolas do município vizinho, de Tavares, o Ensaio é "[...] uma forma coreográfico-musical que combina canto antifonal (solo-coro) e instrumentos de percussão. É performatizado apenas por homens, em situação de pagamento de promessa" (LOBO, 2010, p. 19). No ritual, o(a) dono(a) da casa que recebe o grupo que conduz o Ensaio oferece aos presentes uma refeição que, normalmente, no passado, era composta por feijão-sopinha (sopa de feijão-sopinha, feijão-sopinha com siri, com carne de porco ou galinha).

Com relação à origem do milho-catete, o qual também é conhecido como milho-branco, foi relatado que o alimento é uma herança dos povos indígenas que habitavam a região. Antigamente, a farinha de milho-catete era muito consumida no município, especialmente para fazer pão e angu, pois a farinha de trigo era um produto de alto valor comercial, sendo consumido apenas pelas pessoas de maior poder aquisitivo.

O reconhecimento do valor imaterial desses alimentos que se ligam à ancestralidade quilombola e indígena é destacado logo no início da conversa com os atores locais, como ilustra a fala a seguir: "Esse feijão e o próprio milho catete não tem preço, tem um valor histórico, tem um valor sentimental muito grande" (Participante 3 ).

Algo que merece destaque é que, conforme apontaram os participantes da pesquisa, tanto o cultivo quanto o consumo do Feijão Sopinha e do Milho Catete, embora reconhecidos em seu valor sociocultural, foram perdendo espaço no campo e na mesa para outros cultivos em larga escala, como as plantações de arroz, soja, pinus e mesmo para outros alimentos que foram incorporados 
nos hábitos alimentares da população. Cabe mencionar que, no município de Mostardas, há uma intenção/movimento por parte da COOPTRAM e do Sindicato dos Trabalhadores Rurais (STR) para se estimular a produção destes e de outros alimentos da sociobiodiversidade circunscritos no contexto local, entretanto a sua produção ainda se restringe a pouquíssimos agricultores.

Ainda como causa dessa situação, a comunidade reconhece o papel que a modernização agrícola desempenhou, conforme apresentam as falas a seguir. Em um dos relatos, aparece, inclusive, a extinção como sendo um tipo de "violência".

O feijão sopinha foi basicamente extinto, porque o pessoal também não tinha o conhecimento do seu valor nutricional e juntamente com outras coisas, a modernidade, vai se extinguindo [...]. (Participante 3).

Com o negócio da transgenia, não se vê mais o milho branco, talvez tenha ali no alto Uruguai, porque tem muito indígena ali, talvez alguém tenha. (Participante 3).

É uma violência muito grande, porque ele [feijão-sopinha] não gasta adubo, nem veneno, não gasta nenhum fungicida, talvez seja por isso que ele foi extinto. E tendo essa capacidade de alimentar que ele tem, de retirar do solo aquilo que outras plantas não conseguem retirar. (Participante 8).

O processo de modernização da agricultura, também conhecido como "Revolução Verde", iniciado nos anos 1960, caracterizado pela mecanização do campo e uso de sementes híbridas e insumos químicos (pesticidas e fertilizantes) (ALBERGONI; PELAEZ, 2007), vem desencadeando, desde então, repercussões negativas nos mais diversos contextos, materializando-se pela "[...] passagem de ecossistemas muito diversificados para outros hiperespecializados e integrados em amplos sistemas de produção agroalimentar, em escala internacional” (CONTRERAS, 2005, p. 132). Ademais, os impactos desse modelo de produção, que opera na lógica do lucro, da mercantilização dos alimentos e das relações agrícolas, incidem sobre os planos econômicos, sociais e culturais, colocando, principalmente, os agricultores familiares em situação de exclusão e vulnerabilidade. As consequências têm, ainda, ocasionado efeitos de grandes proporções no meio ambiente, como a contaminação dos solos e das águas, a perda de diversas espécies vegetais e animais, culminando, assim, na redução do patrimônio genético e na homogeneização das paisagens (ALBERGONI; PELAEZ, 2007; RIBEIRO; JAIME; VENTURA, 2017; JOHNS; EYZAGUIRRE, 2006).

Cabe, no entanto, destacar que, na contramão dos efeitos negativos da modernização da agricultura, da extinção de espécies e resistindo enquanto bem imaterial, aparece para a comunidade de Mostardas a figura de uma anciã, ou seja, a figura da tradição, que foi quem contribuiu para a permanência das sementes do feijão-sopinha. Antes de morrer, a mulher teria pedido a um morador da comunidade para que guardasse as poucas sementes que haviam lhe restado e plantasse, para que não se perdessem. O morador, conforme o pedido, plantou as sementes e continuou com a tradição. A partir disto, o feijão teria passado a ser cultivado na região por mais famílias.

O feijão-sopinha e o milho-catete são compreendidos pela comunidade local como alimentos representativos da sua cultura e identidade alimentar, representando, assim, um elo de ligação entre os acontecimentos do passado e as particularidades do presente. A presença desses alimentos na vida dos atores locais se materializa no preparo de receitas contendo os referidos produtos da sociobiodiversidade, as quais, apesar de não serem mais consumidas e elaboradas cotidianamente, continuam sendo preparadas em determinadas ocasiões, como festividades e encontros de família. Inspiradas nas lembranças dos bons sabores do passado, as 
mulheres participantes da oficina culinária resgataram, em suas memórias, práticas culinárias herdadas de seus antepassados. As receitas escolhidas pelas próprias participantes, para serem reproduzidas no dia da atividade, eram preparos de família carregados de afetos e lembranças dos tempos em que as mães e avós reproduziam as receitas e passavam para as demais integrantes da família as técnicas culinárias?

A partir dessa experiência coletiva, foi possivel apreender nas expressões corporais, nas falas e nas sensações despertadas que, entre os sabores e saberes relacionados às receitas com produtos da sociobiodiversidade, as histórias, os significados e o saber-fazer das preparações permanecem vivos entre as pessoas do lugar. Nessa lógica, as preparações a base de milho-catete e feijão-sopinha dialogam com a ideia de patrimônio alimentar, entendendo que os componentes materiais (como os alimentos e utensílios) e imateriais (a exemplo, as práticas, os saberes e as representações) das culturas alimentares são apreendidos como heranças compartilhadas por uma coletividade (MATTA, 2012).

Além de associados a um patrimônio imaterial que alimenta e materializa a identidade, esses alimentos podem também ser considerados um bem material, que aparece, por sua vez, nas referências às suas características sensoriais, seu sabor, como se destaca a seguir, ou mesmo seu valor nutricional, como será tratado na seção seguinte. Ou seja, possuem capacidade de alimentar tanto as histórias, o imaginário, os sentidos despertados pela comensalidade, como também o corpo físico.

Os alimentos da gente aqui tem diferença dos outros alimentos. Prova um milho plantado aqui e um milho comprado de fora, não tem o mesmo gosto. Não tem gosto. (Participante 6).

Esse milho que vem de outra região parece que não alimenta. (Participante 5).

A partir do exposto, apreende-se que o feijão-sopinha e o milho-catete, para além de serem alimentos que remetem a uma determinada cultura e história, ou seja, de terem um valor sociocultural, mostraram-se como dispositivos capazes de nutrir um paladar que une indivíduos de diferentes origens e etnias, bem como de potencializar o valor nutricional da alimentação.

\subsection{Do simbólico ao nutricional: a composição química dos alimentos da sociobiodiversidade}

Os alimentos da sociobiodiversidade foram também analisados pelo campo da Nutrição, ou seja, pela ótica do seu valor biológico e potencialidade nutricional. Nesse sentido, foram realizadas análises de composição química do feijão-sopinha e do milho-catete, as quais são apresentadas nas Tabelas 1 e 2. Nessas tabelas, há também uma comparação, a partir de dados da Tabela Brasileira de Composição dos Alimentos (NEPA, 2011), com valores nutricionais de outros alimentos, como o feijão-preto e a farinha de milho-amarelo, os quais foram utilizados para comparação por serem espécies mais conhecidas e empregadas na culinária de uma forma geral.

\footnotetext{
${ }^{9}$ As receitas selecionadas e reproduzidas pelas participantes da oficina culinária foram as seguintes: feijão-sopinha com siri; caldinho de feijão-sopinha; bolo de milho-catete; bolo de milho-catete com ora-pro-nóbis; biscoito de milho-catete com araruta e nata; biscoito de milho-catete com ora-pro-nóbis; polenta com farinha de milho-catete e suco de cacto-tuna com limão.
} 
Tabela 1 - Composição centesimal $\left(100 \mathrm{~g}^{-1}\right)$ de amostra de feijão-sopinha e comparação com feijão-preto

\begin{tabular}{ccc}
\hline Constituintes & Feijão-sopinha & Feijão-preto $^{\alpha}$ \\
\hline Umidade & $15,36 \pm 0,31$ & 14,9 \\
Proteínas & $24,28 \pm 1,13^{*}$ & 21,3 \\
Lipídeos & $0,61 \pm 0,07^{*}$ & 1,2 \\
Cinzas & $3,83 \pm 0,26$ & 3,8 \\
Fibras totais & $20,32 \pm 1,17$ & 21,8 \\
Carboidratos & $35,6^{*}$ & 58,8 \\
\hline
\end{tabular}

Legenda: Os resultados são médias de triplicatas \pm desvio-padrão; $\left({ }^{*}\right)$ Indica diferença significativa $(\mathrm{P}<0,05)$ pelo Teste de t de Student.

Fonte: ${ }^{\alpha}$ Composição química do feijão preto: (NEPA), 2011.

Tabela 2 - Composição centesimal em $100 \mathrm{~g}^{-1}$ de amostra de farinha de milho-catete e farinha de milho-amarelo

\begin{tabular}{ccc}
\hline Constituintes & Farinha de milho-catete & Farinha de milho-amarelo $^{\alpha}$ \\
\hline Umidade & $12,76 \pm 0,12$ & 11,8 \\
Proteínas & $11,06 \pm 0,41^{*}$ & 7,2 \\
Lipídeos & $2,38 \pm 0,28^{*}$ & 1,5 \\
Cinzas & $1,66 \pm 0,11^{*}$ & 0,5 \\
Fibras Totais & $12,41 \pm 0,73^{*}$ & 5,5 \\
Carboidratos & $59,73^{*}$ & 79,1 \\
\hline
\end{tabular}

Legenda: Os resultados são médias de triplicatas \pm desvio padrão; $\left({ }^{*}\right)$ Indica diferença significativa $(P<0,05)$ pelo Teste de $t$ de Student.

Fonte: ${ }^{\alpha}$ Composição química da farinha de milho média: NEPA (2011).

Os valores encontrados a partir da análise físico-química, demonstram que o Feijão Sopinha apresenta 14\% mais proteínas, 49\% menos lipídios e 39\% menos carboidratos quando comparado ao feijão-preto. Em relação a cinzas e umidade, não houve diferença significativa.

Já a farinha de milho-catete, quando comparada à farinha de milho-amarelo, apresenta maior conteúdo de proteínas (54\%), cinzas (232\%), lipídeos (59\%) e fibras totais (126\%). Além disso, o teor de carboidratos foi $24 \%$ inferior ao conteúdo da farinha de milho-amarelo. Em relação à umidade, não houve diferença significativa.

A partir da comparação apresentada, pode-se verificar a superioridade nutricional dos alimentos da sociobiodiversidade analisados, em relação a outros alimentos comumente consumidos pela população no geral. Essa qualidade nutricional se refere ao maior aporte de proteínas, nutriente que desempenha papel importante em diversos processos biológicos no corpo humano, como produção de células, tecidos e hormônios, por exemplo. As fibras, por sua vez, também possuem diversos efeitos fisiológicos importantes, como auxílio no controle da glicemia e promoção da saúde intestinal. Ambos os alimentos apresentaram menor conteúdo de carboidratos, nesse sentido salienta-se que o consumo excessivo de carboidratos simples pode contribuir para o desenvolvimento de doenças crônicas não transmissíveis (PHILIPPI, 2014).

Desse modo, diante dos achados do que representa a sociobiodiversidade para a comunidade de Mostardas, é possível tecer diferentes análises em relação aos seus efeitos, que 
se estenderiam desde dimensões socioculturais, até as nutricionais. Assim, apreende-se que o uso do feijão-sopinha e do milho-catete, especialmente no âmbito da alimentação escolar, teria capacidade de contribuir com a Segurança Alimentar e Nutricional no contexto local. Partindo, então, dessa discussão, adentra-se na seção seguinte, descrevendo e analisando o lugar que a escola ocupa na vida local, assim como o papel que ela desempenharia caso se ofertassem, de modo mais orgânico, esses alimentos da sociobiodiversidade na alimentação escolar.

\subsection{O lugar da escola na alimentação das crianças}

Acerca do papel da escola, as falas a seguir ilustram a centralidade que esse ambiente teria, no entendimento da comunidade local, sobre o processo de formação de opinião, assim como a forte influência sobre a educação das crianças, sobretudo no que tange ao comportamento alimentar. Todavia os participantes mencionam que haveria divergência entre os cardápios escolares e os hábitos alimentares locais, o que, mais uma vez, aparece como um tipo de "violência", de desrespeito a sua cultura.

Existe uma violência ritual, que o pai e a mãe em casa ensinam um tipo de alimentação e a escola vai lá com a nutricionista e distorce. Daí o grande problema, que a gurizada, para se sentir aceito, ignora o daqui. [...] Quem educa mais hoje é a escola, diferente do meu tempo, que era o pai, a mãe e a avó que tinham a autoridade, elas que educavam. (Participante 5).

Ademais, apareceu também nas falas dos participantes as transformações na alimentação escolar. A "merenda", como mencionaram, era composta, principalmente, por alimentos in natura e produzidos pelas famílias dos próprios alunos, como frutas, bergamota, laranja e lima, e outros vegetais, como batata-doce, aipim e feijão-miúdo. Entretanto, no atual contexto, relatam que há uma presença importante de produtos industrializados, conforme os relatos apresentados:

Antes as escolas viviam a realidade de nós. [...] Agora hoje já temos essas coisas industrializadas. (Participante 3).

Lembra do cacau, do que eles faziam? Agora é o chocolate, antigamente era cacau e não tinha açúcar, daí a gente tinha que levar de casa o açúcar quem queria para temperar o cacau. (Participante 9).

De modo geral, observa-se que o ambiente escolar, seja a partir das relações sociais, do que é oferecido nas refeições ou mesmo abordado em sala de aula em termos de conteúdo, é reconhecido pela comunidade por sua capacidade de interferir em hábitos; entretanto, no que tange a esse aspecto, há uma insatisfação relativa, em especial a falta de diálogo entre os cardápios escolares, a diversificação agrícola da região e os repertórios alimentares. A respeito disso, houve consenso entre os participantes da pesquisa de que a inclusão de alimentos da sociobiodiversidade na alimentação escolar resultaria em modificações positivas nessa interferência, em direção a diversos efeitos benéficos para os alunos, os agricultores e a dinâmica local. Nesse sentido, verifica-se que, apesar dos avanços na legislação que regulamenta o PNAE no que se refere à oferta de refeições escolares pautadas nos princípios da sustentabilidade e da cultura alimentar e no emprego de alimentação saudável e adequada (BRASIL, 2009a), na prática, a situação destacada pela comunidade corrobora outros cenários brasileiros (SOUSA et al., 2015; GIRARDI et al., 2018; GABRIEL et al., 2012).

Ao encontro dessa discussão, Mineiro e Triches (2018), ao buscarem compreender o papel do espaço escolar na cultura alimentar de cinco escolas da etnia Kaingang em Novas Laranjeiras, 
no estado do Paraná, constataram que as escolas vêm contribuindo até mesmo para a aculturação e perda das referências alimentares indígenas. Tal achado provoca a reflexão sobre o lugar que a escola poderia, mas não está ocupando nos processos de valorização dos diferentes modos de vida e no estímulo à construção de hábitos alimentares saudáveis e sustentáveis. Ou seja, a partir da alimentação ofertada, haveria potencialidade para contemplar, além dos aspectos relacionados à saúde e à qualidade de vida, o significado simbólico da alimentação associada à tradição e à cultura, transformando o comer em uma forma de educar tanto pelo ato em si quanto pelo seu desdobramento no currículo escolar.

Além disso, alguns trabalhos (TURPIN, 2009; TRICHES; SCHNEIDER, 2010; BRASIL, 2017a; SOUSA et al., 2015) vêm apontando para outras potencialidades imbuídas na inclusão de alimentos locais na alimentação escolar, como a conservação dos ecossistemas, a autonomia e o empoderamento das famílias agricultoras, a dinamização da economia local, bem como a aproximação entre produtores (agricultores) e consumidores (alunos), por exemplo, contribuindo, assim, para a promoção de paladares que realimentam até mesmo mercados locais.

\section{CONSIDERAÇÕES FINAIS}

Neste artigo, em que se buscou relatar as apreensões acerca do valor sociocultural e nutricional de alimentos da sociobiodiversidade, como o feijão-sopinha e o milho-catete, verificou-se que os referidos alimentos, além de remeterem à história de um passado de luta e resistência e serem dotados de aspectos afetivos, possuem importante capacidade nutricional, devido ao seu aporte de nutrientes.

A respeito da caracterização química, ressalta-se o potencial nutricional do feijão-sopinha e do milho-catete, os quais apresentaram composição nutricional superior quando comparados a outros alimentos habitualmente consumidos, apontando, assim, para a importância do estímulo ao consumo de espécies alimentícias circunscritas no território local, considerando o possível efeito positivo desse consumo sobre a qualidade da alimentação, bem como sobre a saúde da população.

Ademais, para além da importância no plano biológico, é preciso destacar o valor simbólico atribuído ao feijão-sopinha e ao milho-catete, conferindo a tais alimentos o atributo de signo de uma identidade cultural daqueles que partilham de tal paladar. Apesar desse reconhecimento cultural e mesmo das características sensoriais concebidas aos alimentos da sociobiodiversidade em questão, o consumo destes já não é mais tão frequente entre os atores locais, restringindo-se a algumas festividades e encontros de família.

Na contramão da valorização do papel dos alimentos da sociobiodiversidade, a escola, compreendida como um espaço que exerce uma importante influência sobre os hábitos alimentares dos estudantes, não estaria utilizando todo o seu potencial, pela ótica da população local, para a reafirmação das tradições alimentares locais, especialmente no que tange à oferta de refeições que prezem pela diversificação agrícola da região e pelas particularidades culturais. Nesse sentido, reitera-se a importância dos movimentos de inclusão de alimentos da sociobiodiversidade na alimentação escolar, considerando a possível repercussão positiva dessa iniciativa no município, no tocante à promoção da SAN e da soberania alimentar. 


\section{REFERÊNCIAS}

ALBERGONI, L.; PELAEZ, V. Da revolução verde à agrobiotecnologia: ruptura ou continuidade de paradigmas? Revista de Economia, Curitiba, v. 33, n. 1, p. 31-53, 2007.

ASSOCIATION OF OFICIAL ANALYTICAL COLLABORATION INTERNATIONAL [AOAC INTERNATIONAL]. International. Official methods of analysis of AOAC international. 16. ed. Gaithersburg, MD, USA: Association of Analytical Communities, 1997.

BRASIL. Ministério da Agricultura, Pecuária e Abastecimento; Ministério do Meio Ambiente. Portaria Interministerial MAPA/MMA n. 10, de 21 de julho de 2021. Institui lista de espécies nativas da sociobiodiversidade de valor alimentício, para fins de comercialização in natura ou de seus produtos derivados. Diário Oficial da União, Brasília-DF, 22 jul. 2021.

BRASIL. Ministério da Agricultura, Pecuária e Abastecimento. Portaria n. 141, de 8 de janeiro de 2019. Determina os preços mínimos para os produtos extrativos da safra 2019. Diário Oficial da União, BrasíliaDF, 10 jan. 2019.

BRASIL. Ministério do Meio Ambiente. Portaria Interministerial n. 284, de 30 de maio de 2018. Institui a lista de espécies da sociobiodiversidade, para fins de comercialização in natura ou de seus produtos derivados, no âmbito das operações realizadas pelo Programa de Aquisição de Alimentos - PAA. Diário Oficial da União, Brasília-DF, 10 jul. 2018a.

BRASIL. Ministério do Meio Ambiente. Secretaria de Biodiversidade. Biodiversidade Brasileira: sabores e aromas. Brasília-DF: Ministério do Meio Ambiente, 2018b.

BRASIL. Ministério da Educação. Fundo Nacional de Desenvolvimento da Educação. Boas práticas de agricultura familiar para a alimentação escolar. Brasília-DF: FNDE, 2017a.

BRASIL. Ministério da Educação. Fundo Nacional de Desenvolvimento da Educação. Manual para aplicação dos testes de aceitabilidade no Programa Nacional de Alimentação Escolar (PNAE). 2. ed. Brasília-DF: FNDE, 2017b.

BRASIL. Ministério da Educação. Fundo Nacional de Desenvolvimento da Educação. Cartilha Nacional da Alimentação Escolar. Brasília-DF: FNDE, 2014a.

BRASIL. Ministério da Saúde. Secretaria de Atenção à Saúde. Departamento de Atenção Básica. Guia alimentar para população brasileira. 2. ed. Brasília-DF: Ministério da Saúde, 2014b.

BRASIL. Ministério da Educação. Lei n. 11.947, de 16 de junho de 2009. Dispõe sobre o atendimento da alimentação escolar e do Programa Dinheiro Direto na Escola aos alunos da educação básica; altera as Leis n. 10.880, de 9 de junho de 2004, 11.273, de 6 de fevereiro de 2006, 11.507, de 20 de julho de 2007; revoga dispositivos da Medida Provisória n. 2.178-36, de 24 de agosto de 2001, e a Lei n. 8.913, de 12 de julho de 1994; e dá outras providências. Diário Oficial da União, Brasília, DF, 16 jun. 2009a.

BRASIL. Ministério do Desenvolvimento Agrário; Ministério do Meio Ambiente; Ministério do Desenvolvimento Social e Combate à Fome. Plano nacional de promoção das cadeias de produtos da sociobiodiversidade. Brasília, DF, 2009b.

BRASIL. Ministério do Meio Ambiente. Secretaria de Biodiversidade e Florestas. Agrobiodiversidade e Diversidade Cultural. Brasília-DF: Ministério do Meio Ambiente, 2006. (Série Biodiversidade, v. 20).

CARVALHO, A. S.; OLIVEIRA E SILVA, D. Perspectivas de segurança alimentar e nutricional no quilombo 
de Tijuaçu, Brasil: a produção da agricultura familiar para a alimentação escolar. Interface: Comunicação, Saúde, Educação, Botucatu, v. 18, n. 50, p. 69-83, 2014.

CARVAlho, H. H.; JONG, E. V.; BELLÓ, R. M.; SOUZA, R. B.; TERRA, M. F. Alimentos: métodos físicos e químicos da análise. Porto Alegre: UFRGS, 2002.

CASAGRANDE, A. Dinâmicas ambientais e produção do conhecimento intergeracional nas comunidades da Lagoa do Bacupari e de remanescente de quilombo da Casca no litoral do Rio Grande do Sul. 2012. Dissertação (Mestrado em Desenvolvimento Rural) - Faculdade de Ciências Econômicas, Universidade Federal do Rio Grande do Sul (UFRGS), Porto Alegre, RS, 2012.

COELHO-DE-SOUZA, G. Verbetes agrobiodiversidade, agroecologia, agrofloresta, etnoconservação, gestão da biodiversidade, sociobiodiversidade. In: MEDEIROS, M. F. T.; ALBUQUERQUE, U. P. (Org.). Dicionário Brasileiro de Etnobiologia e Etnoecologia. Recife: NUPEEA, 2012. p. 18-64.

CONTRERAS, J. Patrimônio e globalização: o caso das culturas alimentares. In.: CANESQUI, A. M; GARCIA, R. W. D. (Org.). Antropologia e nutrição: um diálogo possível. Rio de Janeiro: Fiocruz, 2005. p. 129-45.

GABRIEL, C. G.; COSTA, L. C. F.; CALVO, M. C. M.; VASCONCELOS, F. A. G. Planejamento de cardápios para escolas públicas municipais: reflexão e ilustração deste processo em duas capitais brasileiras. Revista de Nutrição, Campinas, v. 25, n. 3, p. 363-72, 2012.

GIRARDI, M. W.; FABRI, R. K.; BIANCHINI, V. U.; MARTINELLI, S. S.; CAVALLI, S. B. Oferta de preparações culinárias e alimentos regionais e da sociobiodiversidade na alimentação escolar: um estudo na Região Sul do Brasil. Segurança Alimentar e Nutricional, Campinas, v. 25, n. 3, p. 29-44, 2018.

JOHNS, T.; EYZAGUIRRE, P. B. Linking biodiversity, diet and health in policy and practice. Proceedings of the Nutrition Society, Cambrigde, v. 65, n. 2, p. 182-89, 2006.

LOBO, J. C. Entre gingas e cantigas: etnografia da performance do Ensaio de Pagamento de Promessa Quicumbi entre os morenos de Tavares. Dissertação (Mestrado em Antropologia Social) - Instituto de Filosofia e Ciências Humanas, Universidade Federal do Rio Grande do Sul, Porto Alegre, 2010.

MACIEL, M. E. Identidade cultural e alimentação. In.: CANESQUI, A. M; GARCIA, R. W. D. (Org.). Antropologia e nutrição: um diálogo possível. Rio de Janeiro: Fiocruz, 2005. p. 49-55.

MATTA, R. El patrimonio culinario peruano ante Unesco: alguns reflexiones de gastro-política. desiguALdades.net - Research Network on Interdependent Inequalities in Latin America, Berlin, n. 28, p. 1-45, 2012. [Working Paper Series].

MINAYO, M. C. S. O desafio do conhecimento: pesquisa qualitativa em saúde. 10. ed. São Paulo: HUCITEC, 2007.

MINEIRO, S. K.; TRICHES, R. M. O papel do ambiente escolar na cultura alimentar Kaingang: o caso da Terra Indígena Rio das Cobras, PR. Interações, Campo Grande, MS, v. 19, n. 4, p. 757-71, 2018.

MONTEIRO, C. M.; CANNON, G.; MOUBARAC, J. C.; LEVY, R. B.; LOUZADA, M. L. C.; JAIME, P. C. The UN Decade of Nutrition, the NOVA food classification and the trouble with ultra-processing. Public Health Nutrition, Cambrigde, v. 21, n. 1., p. 5-17, 2017.

NÚCLEO DE ESTUDOS E PESQUISAS EM ALIMENTAÇÃO [NEPA]. Universidade Estadual de Campinas [UNICAMP]. Tabela Brasileira de Composição de Alimentos [TACO]. 4. ed. rev. e ampl. Campinas: UNICAMP, 2011. 
PELEGRINI, F. F. A. Percepção ambiental da comunidade de Mostardas na importância e conservação do Parque Nacional da Lagoa do Peixe, 2012. RS. Tese (Mestrado em Biologia) - Universidade do Vale do Rio dos Sinos [UNISINOS], São Leopoldo, RS, 2012.

PHILIPPI, S. T. Pirâmide dos alimentos: fundamentos básicos da nutrição. 2. ed. São Paulo: Manole, 2014. POPKIN, B. M. Nutrition, agriculture and the global food system in low and middle income countries. Food Policy, [s.l.], v. 47, n. 1, p. 91-96, 2014.

PROSKY, L.; ASP, N. G.; SCHWEIZER, T. F.; DEVRIES, J. M.; FURDA, I. Determination of total dietary fiber in foods and food products: collaborative study. Journal of the Association of Official Analytical Chemists, Rockville, v. 71, n. 5, p. 1017-23, 1988.

RAMOS, J. D. D. Identidade quilombola: mobilização política e manifestações culturais em Beco dos Coloidianos, Rio Grande do Sul. 2011. Dissertação (Mestrado em Sociologia) - Instituto de Filosofia e Ciências Humanas, Universidade Federal do Rio Grande do Sul [UFRGS], Porto Alegre, RS, 2011.

RAMOS, M. O.; CRUZ, F. T.; SOUZA, G. C.; KUBO, R. R. Cadeias de produtos da sociobiodiversidade no sul do Brasil: valorização de frutas nativas da Mata Atlântica no contexto do trabalho com agroecologia. Amazônica: Revista de Antropologia, [on-line], Belém, v. 9, n. 1, p. 98-131, 2017. Disponível em: https:// periodicos.ufpa.br/index.php/amazonica/article/view/5485. Acesso em: 19 out. 2021.

RIBEIRO, H. I.; JAIME, P. C.; VENTURA, D. Alimentação e sustentabilidade. Estudo Avançados, São Paulo, v. 31, n. 89, p. 185-98, 2017.

SANTILLI, J. Agrobiodiversidade e direito dos agricultores. São Paulo: Editora Peirópolis, 2009.

SOUSA, A. A.; SILVA, A. P. F.; AZEVEDO, E.; RAMOS, M. O. Cardápios e sustentabilidade: ensaio sobre as diretrizes do Programa Nacional de Alimentação Escolar. Revista de Nutrição, Campinas, v. 28, n. 2, p. 217-29, 2015.

TRICHES, R. M.; SCHNEIDER, S. Alimentação escolar e agricultura familiar: reconectando o consumo à produção. Saúde e Sociedade, São Paulo, v. 19, n. 4, p. 933-45, 2010.

TURPIN, M. E. A alimentação escolar como fator de desenvolvimento local por meio do apoio aos agricultores familiares. Revista de Segurança Alimentar e Nutricional, Campinas, v. 16, n. 2, p. 20-42, 2009 .

VANINI, M. Uso de plantas medicinais em um território quilombola do município de Mostardas - Rio Grande do Sul. 2010. Dissertação (Mestrado em Enfermagem) - Universidade Federal de Pelotas [UFPel], Pelotas, RS, 2010.

\section{Sobre os autores:}

Vanessa Magnus Hendler: Mestre em Desenvolvimento Rural pela Universidade Federal do Rio Grande doSul (UFRGS).Graduada em Nutrição pela UFRGS. E-mail:vanessa.m.hendler@gmail.com, Orcid: https://orcid.org/0000-0002-0271-1143

Luciana Dias de Oliveira: Doutora em Saúde da Criança e do Adolescente pela Universidade Federal do Rio Grande do Sul (UFRGS). Professora do Departamento de Nutrição da UFRGS. Coordenadora de Gestão do Centro Colaborador de Alimentação e Nutrição do Escolar (CECANE/ UFRGS).E-mail: dialu73@hotmail.com, Orcid: https://orcid.org/0000-0002-3438-0668 
Martine Elisabeth Kienzle Hagen: Doutora em Ciências Biológicas (Fisiologia) pela Universidade Federal do Rio Grande do Sul (UFRGS). Professora do Departamento de Nutrição e do Programa de PósGraduação em Alimentação, Nutrição e Saúde (PPGANS/UFRGS).E-mail: martine.hagen@ufrgs.br, Orcid: https://orcid.org/0000.0002.3838.3866

Andrea Mónica Solans: Mestre em Antropologia Social pela Universidade de Buenos Aires (UBA). Professora da Faculdade de Filosofia e Letras da UBA. E-mail: amsolans@hotmail.com, Orcid: https://orcid.org/0000-0002-6687-6406

Queite Marrone Soares da Silva: Doutoranda em Desenvolvimento Rural pela Universidade Federal do Rio Grande do Sul (UFRGS). E-mail: queitemarroneppgdsunimontes@gmail.com, Orcid: https://orcid.org/0000-0003-0924-4434

Louise Barbosa Palma: Acadêmica do Curso de Nutrição da Universidade Federal do Rio Grande do Sul (UFRGS). E-mail: palma.louise@gmail.com, Orcid: https://orcid.org/0000-0001-7827-1204

Vanuska Lima da Silva: Doutora em Ciência dos Alimentos pela Universidade de São Paulo (USP). Professora do Departamento de Nutrição da UFRGS e do Programa de Pós-Graduação em Alimentação, Nutrição e Saúde (PPGANS/UFRGS). Centro Colaborador de Alimentação e Nutrição do Escolar (CECANE/UFRGS). E-mail: vanuska.lima@ufrgs.br, Orcid: https://orcid.org/0000-0002-7482-4489

Alessandro de Oliveira Rios: Doutor em Ciência de Alimentos pela Universidade Estadual de Campinas. Professor no Departamento de Ciência dos Alimentos da Universidade Federal do Rio Grande do Sul (UFRGS). Laboratório de Compostos Bioativos, Instituto de Ciência e Tecnologia dos Alimentos (ICTA). E-mail: alessandro.rios@ufrgs.br, Orcid: https://orcid.org/0000-0001-8860-6928

Larissa Mont'Alverne Jucá Seabra: Doutora em Ciências da Saúde pela Universidade Federal do Rio Grande do Norte (UFRN). Professora do Departamento de Nutrição da UFRN. E-mail: larissaseabra@yahoo.com.br, Orcid: https://orcid.org/0000-0002-1878-4283

Eliziane Nicolodi Francescato Ruiz: Doutora em Desenvolvimento Rural pela UFRGS. Professora do Departamento de Nutrição e do Programa de Pós-Graduação em Desenvolvimento Rural (PGDR/ UFRGS). E-mail: elizianeruiz@yahoo.com.br, Orcid: https://orcid.org/0000-0002-8632-6612 